\title{
INTEGRATING QUALITY ASSURANCE IN PROJECT WORK PLANS OF THE U.S. GEOLOGICAL SURVEY
}

by William J. Shampine, Larry M. Pope, and Michael T. Koterba

U.S. GEOLOGICAL SURVEY

Open-File Report 92-162

Denver, Colorado 


\section{U.S. DEPARTMENT OF THE INTERIOR MANUEL LUJAN, JR., Secretary}

U.S. GEOLOGICAL SURVEY

Dallas L. Peck, Director

For additional information write to:

Chief, Branch of Quality Assurance U.S. Geological Survey Box 25046, Mail Stop 401 Denver Federal Center Denver, CO 80225-0046
Copies of this report can be purchased from:

U.S. Geological Survey Books and Open-File Reports Section Box 25425, Mail Stop 517 Denver Federal Center Denver, CO 80225-0425 


\section{CONTENTS}

Abstract

Introduction

Purpose and scope

Quality assurance in a project work plan

Plan review, approval, and distribution

Project work-plan contents

Introduction

Project proposal-

Project description

Data-quality objectives -

Project report plan

Project organization and responsibilities

Data collection

Data processing

Reviews-

Data analysis and interpretation

Remedial actions

Progress and quality assurance reports-

Summary

Selected references

Glossary

Figure 1. Organization chart of the Water Resources Division of the

U.S. Geological Survey, 1991

\section{TABLE}

Page

Table 1. Contents of a project work plan, including quality assurance activities 


\title{
INTEGRATING QUALITY ASSURANCE IN PROJECT WORK PLANS OF THE U.S. GEOLOGICAL SURVEY
}

\author{
By William J. Shampine, Larry M. Pope, and
}

Michael T. Koterba

\begin{abstract}
The objectives for including quality assurance procedures in a project work plan are to ensure that the quality of the data collected is defined and is appropriate for the objectives of the investigation. The data-quality information can be used in the interpretation of the data. A project work plan that includes quality assessment provides definable benefits such as clarity of expectations, a method for obtaining a set of data that is expected and has been proven valid, a documentation trail, products that are produced on time and that meet project objectives, and a decrease in work that is lost or redone. Project chiefs must prepare and can publish the work plan for scientific investigations. An expanded outline of a framework that can be used to prepare a project work plan that includes quality assurance is described in this report and contains the following topics: data-quality objectives; project organization and responsibilities; data collection; data processing; project reviews; data analysis; remedial actions; project progress reports and quality assurance reports to management.
\end{abstract}

\section{INTRODUCTION}

The U.S. Geological Survey (USGS) collects and disseminates information about the quality and quantity of water in streams, lakes, and aquifers. Through cooperative and collaborative programs with local, State, and other Federal agencies, the USGS monitors the water resources at sites throughout the Nation and investigates the occurrence, availability, and quality of water in numerous study areas.
Information obtained from data-collection programs, investigative studies, and research efforts is made available to the public, waterresource managers, regulators, and developers through annual data reports, interpretive reports, and open-file reports.

As the Nation's principal earth-science information agency, the USGS has a worldwide reputation for collecting accurate data and producing factual and impartial interpretive reports. Methods for data collection and analysis that were developed by the USGS have become standard techniques used by numerous Federal, State, and local agencies and by private enterprises. The standards of professional conduct, attention to detail, and review that characterize the routine activities of the USGS give users of our products a sense of confidence and a trust in the accuracy and scientific validity of our work.

The USGS performs its work through small organizational units called projects--data projects and interpretative projects. In data projects information is obtained about the occurrence, quality, quantity, distribution uses, and movement of the Nation's surface and ground waters. Data-project findings are reported in the USGS annual water-data reports. In interpretative projects data also are obtained and reports are produced. These reports are not only used to disseminate waterresources data, they provide scientific and technical assessments and understanding of hydrologic systems.

Both types of projects are based on a management system that is intended to keep 
the project activities focused on the project objectives. A fundamental part of this management system is the project work plan. The broad objectives of the project work plan are to:

- Ensure that the quality of the data to be collected is defined.

- Ensure that the quality of the data to be collected is appropriate for the objectives of the work.

- Establish a process that will produce estimates of the variability of the data to be collected.

- Ensure that all the steps necessary for a successful project have been considered.

The quality assurance (QA) activities that a project intends to accomplish are to be included in the project work plan. These QA activities are to include all elements of the scientific work conducted by or for the project. Therefore, the work plan will identify the definable project needs such as:

- Training to ensure that each employee fully understands what is expected from his or her efforts.

- Data that have documented bias and precision.

- Products that are produced on time and that meet project objectives.

- Established project remedial-action procedures.

\section{Purpose and Scope}

This document provides guidance for the inclusion of QA into the project work plan for a hydrologic investigation. Application of the guidelines is equally appropriate for data and interpretative projects.

The guidelines described in this report provide specific suggestions that a project chief can use to prepare the project work plan.
Included are descriptions of the essential elements of $Q A$, discussions of the type of information that should be included in the text for each element, and specifications for how work plans prepared by the USGS are reviewed and approved.

\section{Quality Assurance in a Project Work Plan}

After a project is approved by the Office of the Regional Hydrologist (fig. 1) and is funded, the District Chief, with advice from the District staff, selects a project chief. The project chief prepares a detailed project work plan, which describes the technical plans for conducting the project. The work plan includes topics such as project objectives, type of data to be collected, collection procedures and techniques, sampling locations and frequency of sampling, analytical methods, data-analysis techniques, type and number of report products, budget, staffing, and project time lines. Each topic in the work plan has a QA statement that describes the activities needed to assure that the work plan will be implemented and that the data obtained will meet the dataquality objectives of the project. The QA statements include a discussion of the types and objectives of various quality control (QC) samples or activities, the process for deciding where and how many $Q C$ samples or measurements are needed, how the QC data are to be evaluated, and what actions are to be implemented on the basis of $Q C$ results.

The Branch of Quality Assurance (fig. 1) encourages the preparation of a project work plan for any scientific project, regardless of level of complexity. The District Chief or designee is responsible for ensuring that every project also includes QA in the work plan. However, the District Chief may determine that project $Q A$ activities already are described adequately in the QA plan for the District that is administering the project. The decision concerning what QA activities are needed for a project is based on the project complexity; the 





needs of the project chief and of the District; and, possibly, the needs of a cooperator.

If the decision is made that the project work plan is to be published, the project chief is responsible for the preparation of the work plan. The decision to publish the work plan is made early in the process of developing an investigation, probably when the project proposal is written.

\section{PLAN REVIEW, APPROVAL, AND DISTRIBUTION}

At a minimum, the written project work plan is reviewed by the project chief's supervisor to ensure that the plan includes all the factors required to monitor and document the quality of the work to be done. The work plan, which includes the QA activities, is to be approved before any substantive work is undertaken, because an approved work plan is vital as a guidance document for project personnel.

Completion and review of the project work plan and final approval by the District are documented. A copy of the approved work plan is distributed by the project chief to each person who has a major responsibility for the quality of the data to be collected and to the project chief's supervisor. If the work plan is published, there are two distinct benefits to the project and to management: (1) the work plan can be referenced and (2) the work plan is available to the general public.

If any project work is done prior to the approval of the project work plan, the District Chief or a designee needs to approve such work. Data collected under these conditions are obtained using documented or approved USGS methods. Any implications of the work done, before the approval of the work plan, on the quality of the data collected are described in the work plan.

\section{PROJECT WORK-PLAN CONTENTS}

The project work plan is an expansion of the formally approved project proposal and project description. The work plan contains specific data-collection plans, equipment needs, instrumentation requirements, personnel and training responsibilities, budget provisions, and similar elements of the project. The QA activities and the possible remedial actions that will be taken to correct an observed or suspected project deficiency need to be added to the work-plan framework. A list of essential primary elements of a work plan, including QA activities, is described in table 1.

Table 1.--Contents of a project work plan, including quality assurance activities

Introduction

Project proposal

Project description

Data- quality objectives

Project report plan [see Moore and others, $1988,1990]$

Project organization and responsibilities

Data collection

Data processing (includes validation and archiving)

Reviews

Data analysis and interpretation

Remedial actions

Progress report (detailed memorandum)

Quality assurance report

Selected references (optionaI)

Appendices (optional)

Detailed suggestions as to the discussions to be included for each heading in table 1 are presented in subsequent sections of this report.

\section{Introduction}

This section contains brief introductory statements describing how the project operates 
within the context of its organization (district, branch, or office). This part of the project work plan can contain the statement of the need of the project.

\section{Project Proposal}

The content of a project proposal varies depending on the complexity and the magnitude of the planned action. Moreland (1991) states:

\begin{abstract}
*** a project proposal must contain sufficient information for its evaluation for acceptability and adequacy. Acceptability, in summary, means appropriateness of the project for WRD [Water Resources Division] undertaking, its relationship to regional or national issues, and our capability to undertake the work. Adequacy relates to the technical soundness of the proposal, the time allowed for completion, proposed report plans, the level of funding, and the proposed staffing.
\end{abstract}

In addition, the project proposal includes the QA activities required for completion of the project and estimates of the funding for QA activities.

\section{Project Description}

The elements included in the project description are as follows:

- Title and location.

- Purpose or problem.

- Objectives.

- Scope.

- Approach.

- Reports.

- Relation to State and National programs.

- Human resources.

\section{- Funding.}

The purpose of the description is to provide the reader with a brief, clear understanding of the project objectives without having to refer to some other document. The information provided is sufficient to evaluate the adequacy of the planned QA activities and to indicate possible remedies for deficiencies in methods, approach, data collection, analysis, and reports (Moreland, 1991).

\section{Data-Quality Objectives}

This section of the work plan provides a clear description of:

- The data-quality objectives.

- How the data-quality objectives relate to the overall project objectives.

- The procedures to be used that will ensure that the data-quality objectives will be met.

The data-quality objectives are the foundation upon which the QA activities are built. Development of these data-quality objectives for a project is one of the most important aspects of the project-planning process because the data-quality objectives have a significant effect on the personnel and the financial resources needed for the work. The time and resource cost of collecting data increases significantly as the level of quantification and QA of the data increases. Therefore the collection of data of a quality beyond that which is needed for the project is expensive in time and resources.

Data-quality objectives are not necessarily inflexible and can be modified or refined as new information is obtained. These objectives also can vary within the time frame of a project, among the specific project objectives, and among the various cooperators associated with the project. For example, qualitative data could be needed at the start of the project to define the scope of subsequent work that 
requires quantitative data; lake evapotranspiration data can be less accurate than a chemical analysis of the lake water. The project work plan provides for possible modification of the data-quality objectives to meet changes in the project objectives.

After the data-quality objectives of a project are identified, the scope of the QA and QC activities can be planned. The QA objectives include the:

- Detection limits of the method or procedure.

- Precision within and between samples or measurements.

- Bias of the method or procedure.

- Statistical level of confidence of the method or procedure.

- Effect of not meeting the QA objective on the data-quality objective.

For each measurement that is critical to the success of the project, the following should be discussed:

- Pre-specified conditions that automatically require corrective action.

- Personnel required to make a measurement.

- Identification of who initiates corrective action.

- Specific procedures that will be used to take corrective action.

Development of the QA objectives is considered a sequential process, where the project work-plan objectives and requirements are defined first, the data-quality objectives for the project are developed second, and the QA data needs of the project are developed third. The data-quality objectives and the QA data needs are defined in terms of project requirements rather than in terms of the capabilities of the test methods used.
Historically, data and QA objectives commonly have been used to evaluate new technology rather than to meet the particular needs of the project. That practice is discouraged because QA data are not intended to provide information on methods development nor, in most cases, to isolate the source of erroneous data. When the QA objectives are defined in terms of the project data-quality objectives, QA objectives can be attained through the use of the methods chosen to obtain and analyze data. The QA objectives assist the project chief to reach conclusions relevant to the data-quality objectives.

\section{Project Report Plan}

Moore and others $(1988,1990)$ suggest that a topical outline for each planned report be prepared during the first month of a project, and an annotated report outline be prepared during the first 3 to 4 months, assuming a 3year project. Moore and others also present a guideline for preparing a report work plan. The principle two QA components of the report work plan are: (1) review of the time table listed in the report work plan and (2) the remedial action plan that will be used if the time table is not met. The individual responsible to take corrective actions and the scope of these actions is listed in the remedial action plan.

\section{Project Organization and Responsibilities}

The effectiveness of a QA program depends on all the program participants being aware of the project data-quality and QA objectives. All project personnel involved in the investigation need a clear understanding of their QA roles and responsibilities. The project work plan needs to provide the following:

- The identity of who is responsible for ensuring that the QA activities are performed as planned or for making 
any changes that become necessary as the project progresses.

- A description of technical and QA functions and a list of the persons responsible for these functions.

- The locations of contractors and cooperators and identity of the contact official for each contractor and cooperator.

- The procedures for monitoring contractors.

- A description of type, frequency, and mechanisms of communication among the contractor or cooperator.

- A description of the relevant certifications held by the responsible data collectors, analysts, and contractor or cooperator organizations for the performance of their respective tasks.

Charts and tables can be used effectively in this section to show the management structure of the project, lines of communication, and responsibilities. The responsibilities listed should include those of the key individuals responsible for ensuring the collection of valid data and the routine assessment of measurement systems for precision and accuracy. During preparation of the charts and tables, it should be remembered that an effective project work plan is based on the assumptions that: (1) The project staff is responsible for ensuring that the data to be collected by the project will have a known precision and bias, (2) the quality of the data needs to be determined as objectively as possible, and (3) the dataquality objectives are understood by all members of the project.

\section{Data Collection}

The collection of data is planned carefully. This part of the project work plan includes:

- The type, location, frequency, and method of collection for all new data.

- The reasons for adopting a QC datacollection regime.
- The number and types of sites, samples, and measurements needed.

- The QC requirement for each type of site, sample, and measurement.

- The deadlines for the various elements of the project data-collection activities.

- The corrective actions to be taken for any observed or suspected deficiencies in meeting the data-collection deadlines.

The project chief needs to focus on the project data-collection objectives and not have the QA objectives become simply a means of retesting accepted data-collection or analytical methods. The QA data are collected to allow the user to evaluate the project data and to ascertain the suitability of the data analysis and reporting for the project.

The intent of the data-collection part of the project work plan is to determine: (1) If the data-collection activities of the project truly support the data objectives and (2) if the project deadlines for data collection can be met using the resources available to the project chief.

The methods used to collect all data (including QA) generally should be the same. Any practice or procedure that is different should be documented in the project work plan. For example, a field blank should be collected between samples using normal rinsing procedures used for the collection of samples. Fortified (spiked) samples, however, can require special rinse procedures, bottles, or preservatives not used during normal sample collection. Any special handling of QA samples needs to be described in detail in the work plan.

\section{Data Processing}

Depending on the focus of the project, this part of the project work plan might include discussions of the following: 
1. Data entry, storage, and retrieval.

- Procedures to be used to put project data into the computer.

- File names to be used for data storage.

- Locations and storage media of historical data.

- Procedures to be used to retrieve the historical and new project data.

- Names of individuals responsible for data entry, storage, and retrieval.

2. Data validation.

- Criteria to be used to validate data integrity during the collection and reporting of data.

- Procedures for determining outliers and for flagging suspect data.

- Names of individuals responsible for data validation, if not previously specified.

3. Exploratory data analysis (EDA).

- Summary of EDA procedures to be used.

- Documentation of the computer data displays expected.

- Description of predetermined conditions that will require remedial action (such as data variance that is greater than expected).

- Description of the remedial action to be taken to correct any observed or suspected data deficiency.

- Names of individuals responsible for exploratory data analysis and remedial action, if not previously specified.

4. Data reporting.

- Flow chart of the data-handling process that covers all data collection, transfer, storage, recovery, and proc- essing steps, and that includes QC data for the field and laboratory samples.

- Names of individuals responsible for data reporting, if not previously specified.

5. Archiving project files.

- Identification of what is to be archived, the form of the material to be archived, and the location of the archive.

- Procedure for archiving project files.

- Names of individuals responsible for the archiving, if not previously specified.

\section{Reviews}

Major topics to include in this section are:

- A schedule of all USGS planned reviews.

- The personnel responsible for reviews.

- An explanation if no reviews are planned.

- A schedule for any interlaboratory performance-evaluation studies.

Each project work plan describes the review that will be required to monitor the capability and performance of each measurement system. The review consists of an evaluation of all components of the methods to be used to collect and analyze the data to determine the proper selection and use. This review includes a careful evaluation of $Q A$ procedures for the field and the cooperator laboratory. Whether the National Water Quality Laboratory of the USGS or its contractor is the laboratory to be used is stated in the work plan. Reviews normally are completed prior to or shortly after data collection; however, additional reviews need to be done on a regularly scheduled basis for the duration of the project.

After data collection begins, reviews are conducted periodically to determine the accu- 
racy of each measurement system or any of the component parts of the measurement system. The project work plan includes a schedule for conducting reviews of each measurement parameter, including a review of all measurement systems. As part of the review process for water-quality investigations, laboratories being used for the project are required to participate in the analysis of evaluation samples. The work plan indicates the scheduled participation of the laboratory in any interlaboratory performance-evaluation studies.

\section{Data Analysis and Interpretation}

This part of the project work plan describes in detail how the project personnel will analyze and interpret the QA data. Project personnel decide what statistical analysis will be required before data are collected. The work plan includes discussions of:

- Precision of data.

- Bias of data.

- Representativeness of data.

- Completeness of data.

The QA data collected for a project can and is used as a tool for the duration of the project. In addition to providing information about the quality of the environmental data, QA data can be used by the project chief to monitor the progress of the investigation and to recognize a possible need for changes in sample locations or frequency of sampling. Because of their usefulness, the QA data need to be analyzed and interpreted routinely during the project rather than being analyzed and interpreted at the end of the project.

There are many procedures for evaluating the QA data collected. Interpretative procedures that could be used include line plots, graphs, tables, and map representations; many statistical procedures also could be used.
The analysis and interpretation of the QA data for the project are expected to change to meet project requirements. The $\mathrm{QA}$ data generally will group into whole-sample and individual constituent subcategories. QA data for evaluating the integrity of a whole sample or individual constituents in water-quality studies, for example, include:

- Field-measurement data to ensure consistency in the chemistry of water being collected over time.

- Mass balance sums (dissolved cations and anions) from samples collected to aid in evaluating the general bias in dissolved inorganic constituents and in identifying samples that could be outliers.

- Piper-Durov plots or similar plots that display general water chemistry compared to QA sample water chemistry.

- Box plots that display central tendency and general distribution data of individual constituents.

QA data reported by a laboratory usually represent whole-sample QA data. QA data on individual constituents seldom are routinely reported by a laboratory, and the project needs to produce these data. Individual-constituent QA data needed to meet project data-quality objectives are stated in the work plan. If hypothesis testing (Iman and Conover, 1983; Helsel and Hirsch, 1992) is the approach to be used, the null hypothesis is formulated and stated in the work plan. The point is that the planned approach to analyze and interpret data needs to be stated in the work plan.

\section{Remedial Actions}

A remedial-action program is to be developed and defined in the project work plan and needs to include the following topics:

- Predetermined limits for data acceptability that, if not met or are exceeded, require remedial action. 
- Procedures for remedial action.

- Identification of the individual responsible for initiating the corrective action and the individual responsible for approving the corrective action.

Any of the $Q A$ activities described in preceding sections of this report could necessitate corrective actions. These QA activities include the data evaluations; the performance, systems, or project reviews; and the laboratory and interfield comparison studies.

\section{Progress and Quality Assurance Reports}

Project activities are to be reported to a District Section Chief or a discipline specialist at least yearly in a detailed memorandum. This memorandum includes all studies, datacollection activities, project accomplishments, and problems encountered by project personnel. The progress report generally is written and distributed before any District project review.

An important part of project $Q A$ is the evaluation and reporting of the QA program, including discussions of the performance of measurement systems and the data quality. The QA report is part of the progress report and includes:

- Changes in the project QA program that were made since the last $\mathrm{QA}$ report.

- A summary of QA/QC efforts, training, and accomplishments.

- Results of all reviews.

- Significant QA/QC problems, proposed solutions, and results of remedial actions.

- Data-quality assessments in terms of precision, accuracy, representativeness, completeness, and comparability.

- A discussion of whether or not the QA objectives are being met and the resulting effect on technical conclusions.

- Limitations on use of the measurement data and a discussion of the effects such limitations have on the defensibility of the data.

- Documentation and archiving of the QA report in the project files.

The project work plan identifies the makeup of the QA part of the progress report. Also, the work plan identifies the individual responsible to write the $\mathrm{QA}$ report and states who will receive the $\mathrm{QA}$ report. Any corrective or remedial actions taken by project personnel are to be included in the QA report.

\section{SUMMARY}

The mission of the USGS, specifically the Water Resources Division, is to provide hydrologic data and understanding that can be used for the management of the Nation's water resources. As the Nation's principal earthscience information agency, the USGS conducts its activities through operational units called projects. Each project is expected to document its activities through a project work plan. The project work plan is used to ensure that all the steps necessary for a successful project have been considered. Each project work plan includes documentation of the $\mathrm{QA}$ activities of the project.

The inclusion of QA into the project work plan is accomplished by stating the QA activities needed for each topic in the work plan. The project chief is responsible for developing the work plan and for implementing the prescribed QA activities. The work plan must be approved by the District Chief or designee prior to the collection of data.

The primary elements of a project work plan include data-quality objectives, data collection, data analysis, remedial actions, reports to District management, and report preparation. All these activities need to be 
monitored according to written QA procedures so that hydrologic work performed by the USGS produces data of known quality.

\section{SELECTED REFERENCES}

Barcelona, M.J., and others, 1985, Practical guide for ground-water sampling: Illinois State Water Survey, ISWS Contract Rept 375, $94 \mathrm{p}$.

Friedman, L.C., and Erdmann, D.E., 1982, Quality assurance practices for the chemical and biological analyses of water and fluvial sediments: U.S. Geological Survey Techniques of Water-Resources Investigations, book 5, chap. A6, 181 p.

Helsel, D.R., and Hirsch, R.M., 1992, Statistical methods in water resources: Amsterdam, Elsevier Publishers, 502 p.

Iman, R.L., and Conover, W.J., 1983, A modern approach to statistics: New York, Wiley, 497 p.

Keith, L.H., ed., 1988, Principles of environmental sampling: Washington, D.C., American Chemical Society, $458 \mathrm{p}$.

Moore, J.E., Aronson, D.A., Green, J.H., and Puente, Celso, 1988, Report planning and review guide: U.S. Geological Survey Open-File Report 88- 320,61 p.

1990, Report planning, preparation, and review guide: U.S. Geological Survey Open-File Report 89-275, 81 p.

Moreland, J.A., 1991, Quality-assurance plan for water-resources activities of the U.S. Geological Survey in Montana--1991: U.S. Geological Survey Open-File Report 91$194,30 \mathrm{p}$.

Schroder, L.J., and Malo, B.A., 1987, Qualityassurance/quality-control aspects of precipitation monitoring, in 80th Annual Meeting of Air Pollution Control Associa- tion, New York, New York, June 21-26, Paper 87-65.1, 10 p.

See, R.B., Willoughby, T.C., Brooks, M.H., and Gordon, J.D., 1990, Programs and analytical methods for the U.S. Geological Survey acid rain quality-assurance project: U.S. Geological Survey WaterResources Investigations Report 90-4029, $57 \mathrm{p}$.

Taylor, J.K., 1987, Quality assurance of chemical measurements: Chelsea, Mich., Lewis Publishers, Inc., 328 p.

U.S. Geological Survey, 1986, Water Resources Division publications guide--v. 1, Publications policy and text preparation $(2 \mathrm{~d}$ ed.), revised by D.F. Alt and K.T. Iseri: U.S. Geological Survey Open-File Report 87-0205, 429 p.

\section{GLOSSARY}

Terms associated with the word "quality" tend to have subjective meanings to many people. To avoid misconceptions and misunderstandings caused by confusion in terminology, the following definitions are provided for some of the quality-systems terms used in this report.

Blank solution - a solution that is free of the analyte(s) of interest. The blank solution then is used to prepare a variety of types of blank samples.

Blind sample - a sample submitted for analysis whose composition is known to the submitter but unknown to the analyst.

Double-blind sample - a sample whose composition is known by the submitter but submitted to an analyst in such a way that neither its composition nor its identification as a check sample is known to the latter. 
Exploratory data analysis - a philosophy of data examination that minimizes prior statistical assumptions and allows the data to guide the examiner in the choice of the model to be used.

Field blank - a blank solution that is subjected to all aspects of sample collection, field processing, preservation, transportation, and laboratory handling as an environmental sample.

Filter blank - a blank solution that is filtered in the same manner and through the same filter apparatus used for an environmental sample.

Preservation blank - a blank solution that is treated with the same preservatives used for an environmental sample.

Project work plan - a document, usually prepared by the project chief, that presents in specific terms the project objectives, technical approach, data-collection techniques and locations, products, schedule, resources needed, and $Q A$ activities.

Quality assurance $(Q A)$ - all of the planned or systematic actions necessary to provide adequate confidence that a product or service will satisfy given requirements for quality.

Quality control (QC) - the operational techniques and the activities used to fulfill requirements of quality.
Refrigerator blank - a blank solution that is put in the same type of bottle used for an environmental sample and stored adjacent to an environmental sample in a refrigerated storage area.

Replicate samples - group of samples, collected in a manner such that the samples are thought to be essentially identical in composition. Replicate is the general case for which duplicate is the special case consisting of two samples.

Sampler blank - a blank solution that is poured or pumped through the same field sampler used for the collection of an environmental sample.

Shelf (or hold) blank - a blank solution that is put in the same type of bottle used for an environmental sample and stored adjacent to an environmental sample in a storage area.

Splitter blank - a blank solution that is mixed and separated using a field splitter in the same manner and through the same apparatus used for an environmental sample.

Spike sample - a sample to which known concentrations of specific analytes have been added in such a manner as to minimize the change in the matrix of the original sample.

Trip blank - a blank solution that is put in the same type of bottle used for an environmental sample and kept with the set of sample bottles both before and after sample collection. 